\title{
Inventário bibliográfico das pesquisas sobre a juventude adventista: elementos para um estado da arte
}

\author{
Bibliographic inventory on Seventh-day Adventist \\ youth researches: elements of a state of the art
}

Allan Novaes

\section{Resumo}

O presente artigo consiste em um inventário bibliográfico de pesquisas cujo foco e/ou objeto sejam a juventude adventista. Através da busca de termos relacionados à temática em questão em títulos de dissertações, teses, artigos de periódicos, livros ou capítulos de livro e relatórios institucionais foram encontrados 121 estudos acadêmicos em inglês e português. Por meio de análise bibliométrica foram mapeadas informações relevantes das pesquisas sobre jovens adventistas, entre elas: quantidade de publicações, períodos históricos onde há a maior ocorrência de estudos, principais periódicos nos quais estudos sobre a juventude adventista aparecem, temas mais recorrentes achados nos títulos das publicações a partir da aplicação da técnica de nuvem de palavras e pesquisadores mais profícuos no tema. Com esse levantamento, espera-se contribuir com a sistematização, análise e compreensão da produção de conhecimento relacionado à juventude adventista, cujo resultado seja um ponto-de-partida para a construção de um estado da arte sobre a intersecção juventude/adventismo.

Palavras-chave: Juventude. Adventismo. Estado da arte.

\section{Abstract}

This article presents a bibliographic inventory of researches whose focus 
and/or object are the Adventist youth. Through the search of terms related to Adventist youth in titles of dissertations, theses, periodicals, books, book chapters and institutional reports, were found in English and Portuguese 121 academic studies. Applying a bibliometric analysis, there was mapped relevant information from research on Adventist youth, among them: number of publications, historical periods where the greatest number of studies occur, major journals in which studies of Adventist youth appear, more recurring themes found in titles of publications from the application of the words cloud technique, and researchers more productive. With this survey, it is expected to contribute to the systematization, analysis and understanding of the production of knowledge related to Adventist youth, whose result is a starting point for the construction of a state of the art on the youth/Adventism intersection.

Keywords: Youth. Seventh-day Adventism. State of the art.

\section{Introdução}

Pesquisas denominadas como estado da arte, também conhecidas como estado do conhecimento, são uma espécie de inventário bibliográficodescritivo que buscam mapear a produção acadêmica e científica sobre o tema a ser investigado, "à luz de categorias e facetas que se caracterizam enquanto tais em cada trabalho e no conjunto deles, sob os quais o fenômeno passa a ser analisado". ${ }^{1}$ É papel do levantamento do estado da arte buscar responder que aspectos e dimensões do campo em questão vem sendo destacados e explorados em diferentes épocas, lugares e circunstâncias. Assim, esse tipo de pesquisa pode contribuir significativamente para a constituição do campo teórico de uma área do saber, pois procura

identificar os aportes significativos da construção da teoria e da prática [...], apontar as restrições sobre o campo em que se move a pesquisa, as suas lacunas de disseminação, [...] reconhecer as contribuições da pesquisa na constituição de propostas na área focalizada. ${ }^{2}$

\footnotetext{
${ }^{1}$ FERREIRA, N. A., As pesquisas denominadas “estado da arte”, p. 258.

${ }^{2}$ ROMANOWSKI, J. P.; ENS, R. T., As pesquisas denominadas do tipo "estado da arte" em educação, p. 39.
} 
O campo dos estudos da juventude, uma área que tem tido cadeira cativa especialmente nas ciências sociais com a chamada sociologia da juventude, também é objeto de pesquisas do tipo estado da arte. O primeiro estudo de destaque foi o inventário bibliográfico feito por Cardoso e Sampaio $^{3}$ na obra Bibliografia sobre a juventude, em uma época sem o papel facilitador da internet. No entanto, o trabalho mais atualizado são os dois volumes de $O$ estado da arte sobre juventude na pós-graduação brasileira: educação, ciências sociais e serviço social (1999-2006), organizados por Sposito. ${ }^{4}$ Embora não seja um dos temas mais recorrentes nos estudos sobre a juventude de acordo com Sposito, a religião está presente em diversos trabalhos acadêmicos no campo, como é o caso do trabalho de Tavares e Camurça. ${ }^{5}$ É de interesse de pesquisa do autor deste artigo a intersecção juventude/religião, em especial o recorte da juventude adventista do sétimo dia.

A Igreja Adventista do Sétimo Dia no Brasil (IASD) está entre as dez maiores denominações religiosas do país e possui mais de dois milhões de membros, sendo a maioria deles jovens. ${ }^{6}$ É uma denominação com forte presença no universo midiático através de sua malha comunicacional que contempla portais, emissoras de rádio e TV e até mesmo um canal de streaming com conteúdo audiovisual de produção própria - espécie de Netflix adventista chamada Feliz 7 Play - e programas voltados para o público adolescente e jovem. A denominação investe intensamente nos últimos anos em iniciativas que promovam a mensagem adventista de forma mais inteligível e atrativa para adolescentes e jovens. Um dos principais exemplos dessa investida foi o estabelecimento, por parte da sede sul-americana da denominação, da ênfase nas chamadas novas gerações para oito países da América do Sul no quinquênio 2015-2020. ${ }^{7}$

No entanto, o adventismo ainda desperta interesse modesto da academia brasileira como objeto de pesquisa, da mesma forma que ocorre com o protestantismo histórico ou de missão, quando comparado com outros movimentos cristãos como o catolicismo, pentecostalismo e

${ }^{3}$ CARDOSO, R.; SAMPAIO, H. (Orgs.)., Bibliografia sobre a juventude.

${ }^{4}$ SPOSITO, M. (Org.)., O Estado da arte sobre a juventude na pós-graduação brasileira, v.1 e v.2. ${ }^{5}$ TAVARES, F. R.; CAMURÇA, M., “Juventudes” e religião no Brasil: uma revisão bibliográfica, p. 11-46.

${ }^{6}$ FERREIRA, B. et al., O crescimento do Reino, p. 114.

${ }^{7}$ LEMOS, F., Comunicação é ênfase estratégica de adventistas para os próximos cinco anos. 
neopentecostalismo. ${ }^{8} \mathrm{O}$ "não lugar" do adventismo na academia brasileira acompanha o papel periférico das denominações protestantes históricas como tema de pesquisa, sendo coadjuvante em um campo também coadjuvante.

Diante desse cenário, três estudos recentes procuraram mapear a presença do adventismo como objeto de estudo em trabalhos acadêmicos em português, identificando e listando as pesquisas relacionadas à denominação. $\mathrm{O}$ primeiro deles é o artigo de Fuckner, ${ }^{9}$ ao reunir 15 trabalhos sobre a Igreja Adventista nas áreas de História, Antropologia, Sociologia, Educação, Ciências da Religião e Psicologia. ${ }^{10} \mathrm{O}$ segundo trabalho é de Furtado, ${ }^{11}$ cuja varredura é mais abrangente: aos 15 trabalhos listados por Fuckner são acrescentados 43 por Furtado, totalizando 58. O mais recente e abrangente é a obra $O$ adventismo na academia brasileira: um panorama do estado da arte, organizado pelo autor deste artigo e Follis, ${ }^{12}$ que abrange 143 trabalhos de 1976 a 2013. Observouse, todavia, que nos trabalhos citados, especialmente no levantamento mais recente, poucas pesquisas foram feitas na intersecção juventude/adventismo. Dessa forma, diante de uma denominação que promove a juventude como ênfase estratégica para seu planejamento quinquenal, faz-se necessário saber se essa iniciativa político-administrativa é acompanhada de reflexão e produção científica.

O presente artigo retoma os levantamentos feitos, todavia o objetivo aqui é mapear as pesquisas sobre a juventude adventista, conhecendo suas características, peculiaridades e enfoques. É necessário ressaltar, contudo, que é preciso reunir aos estudos em português pesquisas em língua inglesa, dada a realidade já mencionada que em levantamentos anteriores foram poucos os trabalhos acadêmicos encontrados no idioma do Brasil. Para tanto, foi tomado como base o estudo intitulado A compilation of studies related to Seventh-day

\footnotetext{
${ }^{8}$ RIBEIRO, L. M. P., O protestantismo brasileiro: objeto em estudo, p. 72-73; FONSECA, A. B., Muito além do sábado, p. 89; FURTADO, K., Representações escatológico-sabático-dietéticas de jovens da Igreja Adventista do Sétimo Dia.

${ }^{9}$ FUCKNER, I., A Igreja Adventista do Sétimo Dia entre a modernidade e a pós-modernidade, p. $159-169$.

${ }^{10} \mathrm{O}$ ano de 1972, para Fuckner dá início à introdução do adventismo como objeto de estudo na academia brasileira, o que representa uma mudança significativa no olhar sobre os adventistas, já que "até aquele momento a produção bibliográfica restringia-se aos adeptos do próprio adventismo ou a seus opositores - uma produção predominantemente apologética".

${ }^{11}$ FURTADO, K., Representações escatológico-sabático-dietéticas de jovens da Igreja Adventista do Sétimo Dia.

${ }^{12}$ NOVAES, A.; FOLLIS, R. (Orgs.)., O adventismo na academia brasileira: um panorama do estado da arte.
} 
Adventist youth and young adults and their attitudes toward spirituality and the church, de Brantley. ${ }^{13}$ Nele foram selecionados 83 estudos de diversas fontes, relacionando jovens e jovens adultos com suas percepções de igreja, crenças e práticas religiosas. Ele propõe atualizações regulares, preocupandose em oferecer reflexões que ajudem a compreender o desinteresse dos jovens pela religião organizada.

Dessa forma, este artigo apresenta descrições e breves reflexões do panorama das pesquisas realizadas em dissertações, teses, livros, artigos científicos e equivalentes de 1975 a 2018, sempre tendo a juventude adventista como foco ou como um dos objetos da pesquisa. Com esse inventário, esperase contribuir com a sistematização, organização, análise e compreensão da produção de conhecimento relacionado à juventude adventista, cujo resultado seja um ponto-de-partida para a construção de um estado da arte sobre a intersecção juventude/adventismo no circuito acadêmico anglófono e brasileiro.

\section{Panorama das principais pesquisas sobre a juventude na IASD}

A compilação de Brantley é um dos primeiros passos para quem deseja pesquisar o tema "juventude adventista", uma vez que o autor reúne 83 estudos em língua inglesa, como já mencionado em seção anterior. Em seu levantamento é possível perceber que $41 \%$ dos trabalhos possuem o verbete Valuegenesis no título da pesquisa. Esses 34 trabalhos estão espalhados em um intervalo de pelo menos dez anos, fazendo de Valuegenesis não só o termo maior ocorrência, mas também o de maior envergadura temporal. Com esse destaque surge então um interesse especial nessa menção.

O estudo Valuegenesis teve sua primeira publicação em 1992 com a obra Valuegenesis: Faith in the Balance - um livro de 308 páginas publicado pela La Sierra University Press. Na obra, apresenta-se o público-alvo da pesquisa, que pode ser dividido em seis grupos: (1) jovens adventistas do sexto ano do ensino fundamental ao terceiro ano do ensino médio na rede adventista de ensino; (2) jovens adventistas do sexto ano do ensino fundamental ao terceiro ano do ensino médio na rede pública de ensino; (3) pais; (4) professores; (5) diretores da rede de educação adventista; (6) pastores adventistas de igrejas que dão suporte às escolas. Todo o processo de seleção da amostra foi randômico e dentro do território dos Estados Unidos, Canadá e Bermudas.

\footnotetext{
${ }^{13}$ BRANTLEY, P., A compilation of studies related to Seventh-day Adventist youth and young adults and their attitudes toward spirituality and the church.
} 
A pesquisa se mostrou de grande repercussão no circuito acadêmico adventista devido a sua amplitude e profundidade. Os participantes responderam um questionário com 465 perguntas. Participaram da pesquisa 12.142 adolescentes e jovens do ensino fundamental e ensino médio, 1.892 pais, 383 professores, 176 diretores e 155 pastores, totalizando 14.748 respondentes em 271 escolas. O livro Valuegenesis: Faith in the Balance fornece uma análise completa dos dados com insights sobre o significado do papel da igreja local, da escola e da família no desenvolvimento da fé do adolescente e do jovem. ${ }^{14}$

A partir do primeiro livro é possível observar vários desdobramentos como artigos, teses, dissertações e até outros livros. A principal publicação dessa sequência é o livro Valuegenesis - Ten Years Later: A Study of Two Generations de 2004. Outro indicativo da importância acadêmica da série é a quantidade de citações ao termo Valuegenesis encontradas pelo autor deste artigo em busca realizada via Google Scholar: 573 ocorrências. Logo, ao se avançar no inventário bibliográfico ao qual este artigo se propõe, foi considerada a importância e a relevância do estudo Valuegenesis e suas publicações posteriores, ao ponto de incluir o termo Valuegenesis na busca, como apresentado na seção seguinte.

\section{Metodologia}

O presente inventário bibliográfico é cronológico e longitudinal e pode ser dividido em três etapas metodológicas: (1) seleção ampla de material bibliográfico com a utilização do software Zotero, ${ }^{15}$ (2) tratamento das informações com base em técnicas de bibliometria ${ }^{16}$ e, concomitantemente à etapa dois, (3) elaboração de reflexões que melhor traduzam o fenômeno juventude-adventismo na produção acadêmica.

$\mathrm{Na}$ etapa de seleção é importante pontuar alguns recortes utilizados na pesquisa. Selecionou-se apenas trabalhos em português e inglês, como

\footnotetext{
${ }^{14}$ DUDLEY, R. L., Valuegenesis: Faith in the Balance.

${ }^{15}$ Zotero é um programa gerenciador de referências bibliográficas e materiais relacionados a pesquisa em software livre e de código aberto. Suas características principais são a integração com navegadores, sincronização online e geração de citações em texto, rodapés e bibliografias. ${ }^{16}$ Bibliometria é o estudo dos aspectos quantitativos da produção intelectual, com foco em sua disseminação e no uso da informação registrada. TAGUE-SUTCLIFFE, J., An introduction to informetrics, p. 1-3.
} 
já abordado na introdução. A busca se deteve também a seis grupos de trabalhos acadêmicos: dissertações ou teses, livros, capítulos de livros, artigos de periódicos, apresentações em congressos (oral ou pôster) e relatórios institucionais.

Considerou-se três as fontes primárias de busca. A primeira delas foi a compilação de Brantley, ${ }^{17}$ sendo que dos 83 trabalhos catalogados oito foram descartados por terem sido publicados em revistas populares, totalizando 75 trabalhos aproveitados para o corpus da análise. A segunda fonte foi o livro $O$ adventismo na academia brasileira, ao passo que a terceira fonte consistiu na plataforma de pesquisa Google Scholar (GS). Os termos escolhidos para a busca e o levantamento em inglês foram "adventist", "SDA", 18 “youth", "young", "millenials", "valuegenesis" e suas combinações. Já para o português escolheram-se os termos "adventista", “adventismo", "IASD"19, "jovem", “jovens", “juventude", "juvenil" e suas combinações. A ocorrência de um par de termos supracitados no título do trabalho, resumo, ou palavras-chave era o único requisito para a inserção do documento no corpus de análise. Sendo assim, a natureza desse levantamento foi estritamente quantitativa, importando a simples ocorrência e não a relevância do termo no trabalho. Apesar disso, com esse critério de seleção, é possível garantir a aderência do termo ao tema juventude como foco principal de cada estudo.

O período de coleta foi de julho a agosto de 2018 e foram encontrados 121 trabalhos acadêmicos, como se vê na "Tabela 1". Foram desconsiderados os trabalhos de iniciação científica, como os de conclusão de curso, ou publicações em revistas populares.

Tabela 1: Quantidade de trabalhos com ocorrência dos termos por tipo

\begin{tabular}{c|c|c|c|c|c|c}
\hline $\begin{array}{c}\text { Tese ou } \\
\text { dissertação }\end{array}$ & Livro & $\begin{array}{c}\text { Capítulo } \\
\text { de Livro }\end{array}$ & Periódico & $\begin{array}{c}\text { Apresentação } \\
\text { em Congresso }\end{array}$ & Relatório & Total \\
\hline 35 & 10 & 1 & 46 & 9 & 20 & 121 \\
\hline
\end{tabular}

\footnotetext{
${ }^{17}$ BRANTLEY, P., A compilation of studies related to Seventh-day Adventist youth and young adults and their attitudes toward spirituality and the church.

${ }^{18}$ Sigla para Seventh-day Adventist, ou adventista do sétimo dia, em português.

${ }^{19}$ Sigla para Igreja Adventista do Sétimo Dia.
} 


\section{Análise bibliométrica}

Acerca do cenário bibliométrico foram feitas duas análises. A primeira com ênfase cronológica, buscando sempre informações correlacionadas com o passar dos anos. A ideia aqui foi reunir todos os trabalhos de todas as modalidades - dissertações ou teses, livros, capítulos de livros, artigos de periódicos, apresentações em congressos (oral ou pôster) e relatórios institucionais de - 1975 a 2018 - para se ter um retrato geral e amplo da produção acadêmica sobre a juventude adventista. De posse desse panorama, foi possível (1) obter dados acerca da quantidade de estudos acadêmicos sobre juventude adventista por ano, (2) palavras mais citadas nos títulos dos estudos, (3) quantidade de pesquisas por idioma em função do tempo, (4) os cinco autores com maior produção acadêmica na área, e (5) os cinco trabalhos mais citados.

A segunda análise bibliométrica foi realizada ao serem selecionados apenas quatro tipos de trabalhos acadêmicos: dissertações ou teses, livros, capítulos de livros e artigos de periódicos. A escolha se justifica pela amplitude, alcance e volume de conteúdo desses quatro tipos de produções serem significativamente maiores em comparação às outras duas modalidades (apresentações em congressos e relatórios). O objetivo foi registrar impressões mais aprofundadas por tipo de trabalho, como se verá posteriormente.

\subsection{Elementos bibliométricos de todos os tipos de produção acadêmica}

O primeiro estudo produzido sobre juventude no contexto acadêmico adventista foi uma dissertação de mestrado em 1975 pela Andrews University. Esse trabalho buscou encontrar padrões de percepção de valores e desenvolvimento de caráter entre estudantes em um campus universitário confessional. ${ }^{20} \mathrm{Tal}$ ponto de partida traz uma simples, mas importante conclusão: são 43 anos e 121 trabalhos acadêmicos que revelam a preocupação da IASD com as novas gerações. O gráfico abaixo relaciona a quantidade de material acadêmico publicado no decorrer dos anos.

${ }^{20}$ JORDAN, G., Perception of values relating to character development. 
Gráfico 1: Estudos acadêmicos adventistas sobre juventude por ano

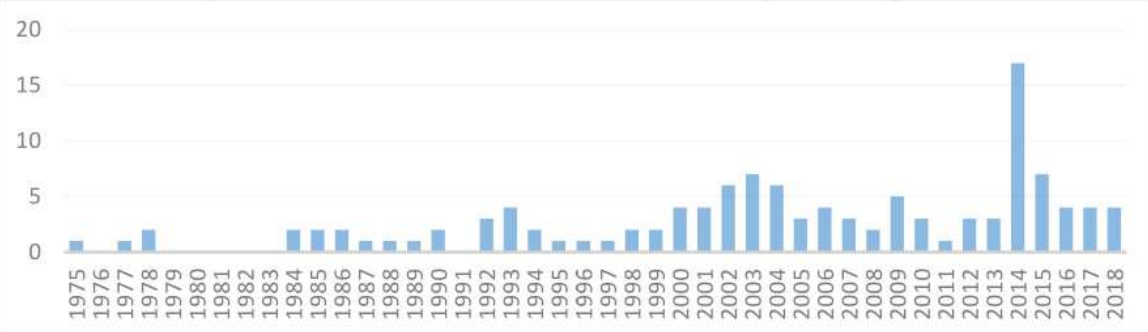

É possível destacar três sequências de anos. A primeira delas de 1979 a 1983, com nenhuma publicação encontrada, representando um início naturalmente modesto da pesquisa sobre juventude na IASD. Já nos anos 20022004 ocorre o primeiro pico de publicação, devido aos 14 relatórios prévios do período, que culminaram no lançamento do livro Valuegenesis - Ten Years Later: A Study of Two Generations. Nesse grupo de relatórios encontra-se um importante estudo encomendado pela administração da IASD na América do Norte ao Barna Group ${ }^{21}$ denominado Seventh-day Adventist Church Young Adult Study. Essa pesquisa com 488 jovens adventistas, entre 18 a 29 anos, destacou em suas conclusões a considerável desconexão entre as atitudes da juventude adventista em relação as crenças doutrinárias e práticas da própria igreja. ${ }^{22}$ Outra curiosidade desse período é em que 2004 foi a única vez que a publicação de dois estudos ocorreu no mesmo ano.

A terceira sequência - e o segundo pico de publicações - aconteceu de 2014 a 2015, sendo marcado pela grande quantidade de teses e dissertações. Em 2014 foram publicados dez títulos, sendo o líder nesse quesito, seguido de 2015 com outros três. Esse período também possui o maior número de publicações em periódicos, com quatro exemplares, assim como a publicação de um importante livro com o título Beyond Beliefs: What Millenial Young Adults Really Think of the 28 Beliefs of the Seventh-day Adventist Church. De acordo com os dados coletados e visualizados por meio do "Gráfico 1", é possível afirmar que as sequências 2002-2004 e 2014-2015 foram os períodos mais importantes na pesquisa sobre os jovens na IASD.

$\mathrm{Na}$ tentativa de melhor entender os temas mais frequentes nos títulos

${ }^{21}$ O Barna Group é uma empresa cristã evangélica especializada em pesquisas de opinião sobre fé e religiosidade sediada na Califórnia, Estados Unidos.

${ }^{22}$ BARNA GROUP., The Seventh day Adventist Millennial Study. 
do corpus de análise utilizou-se a técnica de nuvem de palavras através do site WordArt.com. Essas técnicas consistem em "usar tamanhos e fontes de letras diferentes de acordo com as ocorrências das palavras no texto analisado, gerando uma imagem que apresenta um conjunto de palavras, coletadas do corpo do texto e agregadas de acordo com sua frequência". ${ }^{23}$ Essa frequência de palavras foi contabilizada através do software Antconc.

Para fins de refinamento do método, foi necessário unir os títulos de todas as publicações em um só arquivo e remover os artigos, pronomes, preposições e palavras desconectadas do tema. Também foram agrupadas palavras correlatas tais como adventista e adventismo, teenager e adolescence, entre outras. A "Figura 1" é o resultado desse processo. As palavras como adventist, church, youth, young, Valuegenesis (VG) e study apresentaram destaque. Além dos termos correlatos à juventude, evidencia-se a importância da palavra faith. Ao estudar a juventude, os trabalhos acadêmicos adventistas têm uma grande preocupação em entender como as novas gerações se relacionam com a crença no sobrenatural e de que maneira a fé funciona como lente para o jovem interpretar a realidade ao seu redor, como pode ser visto, por exemplo, nas pesquisas de Thayer ${ }^{24}$ e Dudley. ${ }^{25}$

Figura 1: Nuvem de palavras em todo o corpus de análise

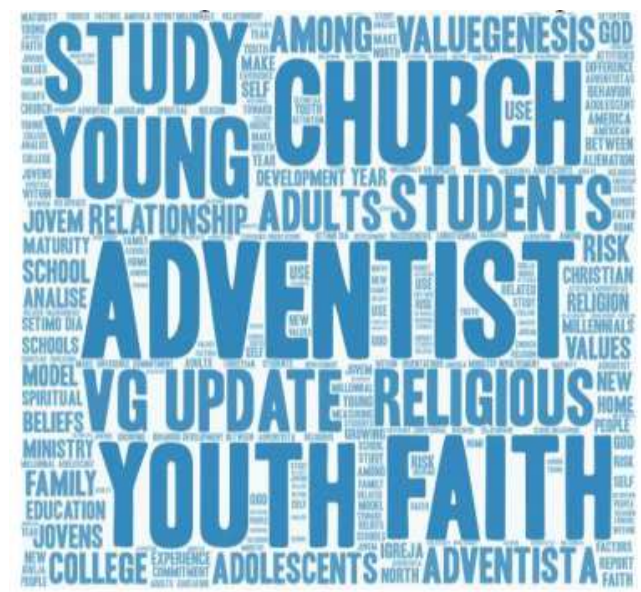

${ }^{23}$ DIAS, M. A. et al., Intersetorialidade e Estratégia Saúde da Família: tudo ou quase nada a ver?, p. 4371-4382.

${ }^{24}$ THAYER, J. D., Measuring faith maturity, p. 93-113.

${ }^{25}$ DUDLEY, R. L., Understanding the spiritual development and the faith experience of college and university students on Christian campuses, p. 5-28. 


\section{O maior número de publicações se dá no idioma inglês. Dos 121 trabalhos}

catalogados, 14 estão em português e os outros 107 em inglês. Olhando para o "Gráfico 2" pode-se perceber que os trabalhos em português começam a ser relevantes a partir de 2004 - um silêncio de quase 30 anos em relação aos norte-americanos. Esses números sugerem que a pesquisa feita sobre juventude adventista no Brasil ainda vive seus primeiros passos, sendo um campo fértil para novos pesquisadores.

Gráfico 2: Publicações por idioma em função do tempo

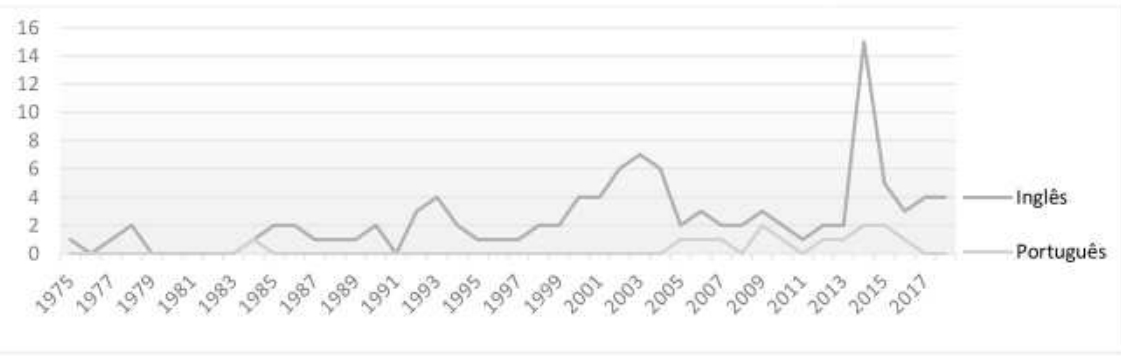

Outro importante dado a ser considerado é a quantidade de citações que um trabalho possui, indicando, de certa forma, sua relevância no cenário acadêmico. Foram ordenados todos os 121 trabalhos com a quantidade de citações apontadas pelo Google Scholar (GS). A seguir, a "Tabela 2" apresenta os cinco primeiros trabalhos no ranking de citações.

Tabela 2: Trabalhos mais citados

\begin{tabular}{c|l|c|c|c|c}
\hline $\begin{array}{c}\text { Ranking } \\
\text { GS }\end{array}$ & \multicolumn{1}{c|}{ Título } & Idioma & Citações & Ano & Tipo \\
\hline $1^{\text {o }}$ & $\begin{array}{l}\text { The effects of maternal parenting style } \\
\text { and religious commitment on self- } \\
\text { regulation, academic achievement, and } \\
\text { risk behavior among African-American } \\
\text { parochial college students }\end{array}$ & Inglês & 167 & 2009 & Periódico \\
\hline $2^{\text {o }}$ & $\begin{array}{l}\text { Transmission of Religious Values from } \\
\text { Parents to Adolescents }\end{array}$ & Inglês & 120 & 1986 & Periódico \\
\hline $3^{\text {o }}$ & Valuegenesis: Faith in the Balance & Inglês & 94 & 1992 & Livro \\
\hline $4^{\text {o }}$ & $\begin{array}{l}\text { Alienation from Religion in Adolescents } \\
\text { from Fundamentalist Religious Homes }\end{array}$ & Inglês & 75 & 1978 & Periódico \\
\hline $5^{\text {o }}$ & $\begin{array}{l}\text { Why Our Teenagers Leave the Church: } \\
\text { Personal Stories from a 10-year Study }\end{array}$ & Inglês & 65 & 2000 & Livro \\
\hline
\end{tabular}


No top cinco vê-se três artigos de periódicos e dois livros. Um indicativo da boa repercussão do primeiro colocado no quesito número de citações é o período recente de publicação comparado com as outras do ranking. Esse estudo procurou encontrar as relações entre a religiosidade de pais e alunos e sua conexão com a educação familiar, desempenho acadêmico e comportamento entre jovens afro-americanos que frequentam uma escola confessional. ${ }^{26}$

O segundo estudo buscou encontrar concordâncias com declarações de valores religiosos de jovens e seus pais em igrejas adventistas por meio de 712 pesquisas individuais. ${ }^{27}$ De acordo com o autor, diferenças significativas foram encontradas entre os jovens e seus pais na escala de atitude e valores religiosos, mostrando que as mães eram as mais tradicionais, seguidas pelos pais, sendo os jovens os menos tradicionais. No entanto, os jovens também foram significativamente correlacionados com seus pais mostrando que a relação entre jovens e mães é um pouco mais forte do que entre jovens e pais nos temas abordados.

Dos cinco trabalhos mais citados, quatro deles vão elaborar de alguma forma a temática pais e filhos, evidenciando que o assunto é reconhecidamente importante na amostra. $\mathrm{O}$ trabalho em português mais citado ocupa a $35^{\circ}$ posição, com somente cinco citações, reforçando a necessidade de avanço em pesquisas nesse tema no Brasil.

$\mathrm{Na}$ tentativa de entender quais os principais pesquisadores nessa área do conhecimento, foram catalogados 109 autores diferentes nos 121 estudos. O pesquisador com maior número de trabalhos publicados é Gillespie Bailey com 25 publicações, como mostra a "Tabela 3". Não se assume que a quantidade de publicações esteja relacionada à qualidade, todavia vale ressaltar que esse pode ser considerado um razoável indicativo dos pesquisadores do circuito acadêmico que mais trabalham com a temática da juventude adventista. Logo, para estudar o tema é preciso conhecer o trabalho desses pesquisadores. Cabe enfatizar que, no corpus de análise, pesquisadores brasileiros estão sempre associados a uma obra somente.

${ }^{26}$ ABAR, B.; CARTER, K. L.; WINSLER, A., The effects of maternal parenting style and religious commitment on self-regulation, academic achievement, and risk behavior among African-American parochial college students, p. 259-273.

${ }^{27}$ DUDLEY, R. L.; DUDLEY, M. G., Transmission of religious values from parents to adolescents, p. 3-15. 
Tabela 3: Principais autores por quantidade de publicações

\begin{tabular}{c|l|c}
\hline Ranking & Autor & Publicações \\
\hline $1^{\text {o }}$ & GILLESPIE, V. B. & 25 \\
\hline $2^{\text {o }}$ & DUDLEY, R. L. & 21 \\
\hline $3^{\circ}$ & GILLESPIE, T. & 17 \\
\hline $4^{\circ}$ & KIJAY, J. & 6 \\
\hline $5^{\circ}$ & PETERSEN, P. B. & 4 \\
\hline $5^{\circ}$ & SIGVARTSEN, J. A. & 4 \\
\hline $5^{\circ}$ & SIGVARTSEN, L. M. & 4 \\
\hline
\end{tabular}

3.2. Elementos bibliométricos de dissertações, teses, artigos, livros e capítulos de livro

Esse primeiro levantamento não tem a pretensão de esgotar todos os trabalhos já realizados até então, porém acredita-se que servirá como forte demonstrativo das tendências de produção acadêmica sobre o tema. Essa seção se limita a abordar teses e dissertações, livros e periódicos procurando as principais nuances como universidades, editoras, revistas e temas. Primeiro é preciso falar sobre as teses e dissertações.

Acredita-se que as teses e dissertações funcionam como um termômetro para entender a importância do tema junto aos programas stricto sensu. Foi possível contabilizar 34 teses e dissertações. Somente a Andrews University é responsável por 22 desses trabalhos, a uma distância de 19 trabalhos do segundo colocado no ranking. Pensando em trabalhos futuros seria pertinente estudar quais motivos desse amplo interesse em pesquisar a juventude adventista.

Tabela 4: Principais Universidades

\begin{tabular}{l|c}
\hline Universidade & Publicações \\
\hline Andrews University & 22 \\
\hline La Sierra University & 3 \\
\hline Western Michigan University & 2 \\
\hline
\end{tabular}


No Brasil, seis instituições de ensino estão representadas, cada uma com uma tese ou dissertação, sendo elas o Centro Universitário Adventista de São Paulo (UNASP), a Universidade Metodista de São Paulo (UMESP), a Escola Superior de Teologia (EST), a Faculdade Adventista da Bahia (FADBA), a Universidade Federal de Pernambuco (UFPE) e, por fim, a Universidade Estadual de Ponta Grossa (UEPG). Citar as universidades brasileiras que já abordaram o tema pode ser proveitoso para pesquisadores que desejam se lançar na temática nesses centros de ensino que já abriram suas portas.

Sobre os conteúdos nas teses e dissertações mais uma vez trabalhouse com a técnica de nuvens de palavras nos títulos dos trabalhos. Algumas palavras foram removidas do corpus de análise por terem sido verbetes de busca tais como "igreja adventista do sétimo dia", "jovens" e seus correlatos. $\mathrm{Na}$ "Figura 2" se destacam as palavras ligadas a educação, tais como "students", "education" e "school". Dessa forma, é possível afirmar com relativa segurança a relevância da área de educação nas teses e dissertações sobre a juventude adventista.

Figura 2: Nuvem de palavras nos títulos de teses e dissertações

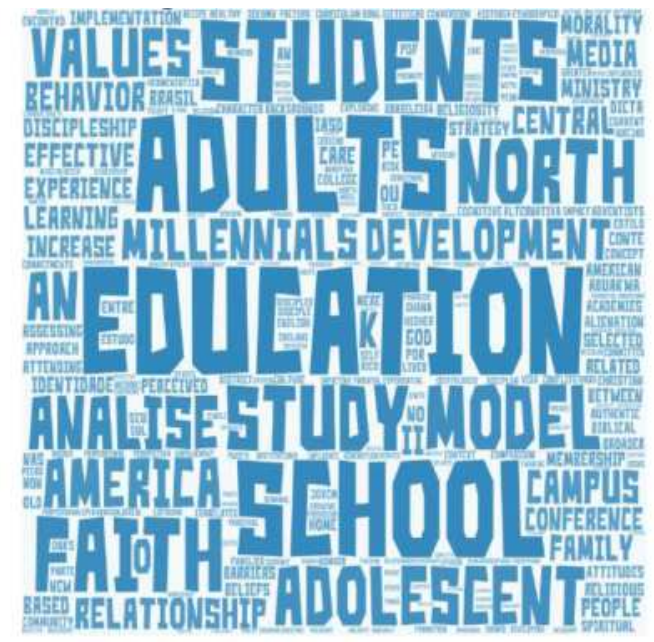

Entre os livros, quatro publicações são da editora adventista norteamericana Review and Herald, sendo seis do mesmo autor, Roger Dudley, cujos dados apontam como o segundo pesquisador mais profícuos com 
trabalhos sobre a juventude adventista. O primeiro livro foi lançado em 1978 e o último em 2009. A somatória das páginas de todos os livros ultrapassa 2.700. A "Figura 3" apresenta as principais palavras nos títulos e seções de livro. O verbete teenager se destaca entre os demais, com cinco ocorrências em 11 oportunidades. Os adolescentes representam uma importante faixa etária na comunidade adventista e parte dessa atenção se deve ao fato de ser uma idade com índices de adesão e evasão marcantes. ${ }^{28}$ O que mantém os adolescentes na igreja é uma questão que motiva vários dos estudos do recorte em questão. O senso de pertencimento é uma das respostas mais indicadas. ${ }^{29}$ Programas e ações que promovam esse senso vem sendo cada vez mais praticados pela liderança da comunidade adventista, de forma que as crenças e a maneira como elas são praticadas pelos jovens também estão em destaque nos títulos dos livros catalogados, conforme figura abaixo.

Figura 3: Nuvem de palavras nos títulos de livros

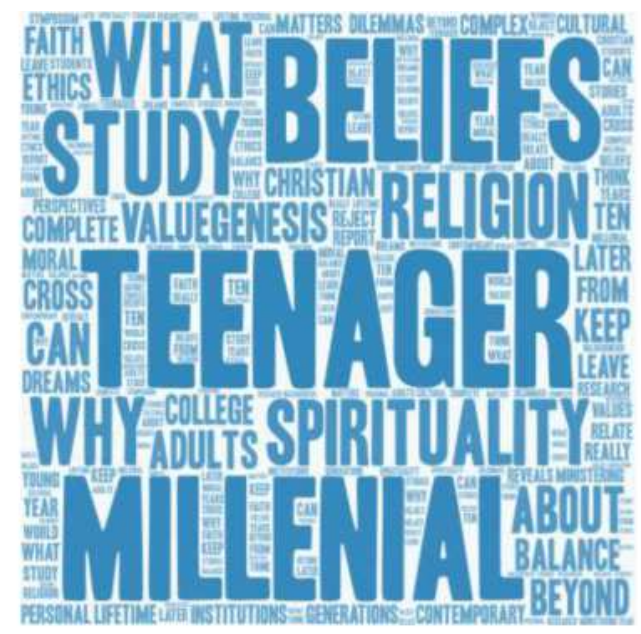

Sobre os artigos científicos é possível perceber que os periódicos mais utilizados são Journal of Adventist Education e Journal of Research on Christian Education com nove publicações, como mostra a "Tabela 5". A

\footnotetext{
${ }^{28}$ FERREIRA, B. et al., O crescimento do Reino.

${ }^{29}$ TETZ, M.; HOPKINS, G. L., We can keep them in the church.
} 
revista Kerygma ocupa um papel de destaque sendo o único periódico em português, classificado no momento da redação deste artigo pela Capes com Qualis C, tendo um total de seis artigos publicados. Dessa forma, a revista Kerygma é o periódico mais importante para o tema juventude e adventismo no Brasil até o momento em que este artigo foi publicado.

Tabela 5: Quantidade de artigos por periódico

\begin{tabular}{l|c}
\hline Revista & Publicações \\
\hline Journal of Adventist Education & 9 \\
\hline Journal of Research on Christian Education & 9 \\
\hline Kerygma & 6 \\
\hline Review of Religious Research & 4 \\
\hline
\end{tabular}

Além da quantidade de artigos, é preciso levar em conta o Fator de Impacto (FI) dos periódicos científicos com o objetivo de aferir a produção científica dos autores e classificar os periódicos científicos inseridos no Journal Citation Reports (JCR) do Institute for Scientific Information ISI. ${ }^{30}$ Além da principal métrica já citada, ferramentas como a rede social acadêmica ResearchGate (RG) também cumpre o papel de avaliar e comparar publicações medindo o "impacto" de pesquisadores e pesquisas. Faz-se necessário lembrar que essa nova ferramenta também é alvo de críticas no circuito acadêmico. ${ }^{31}$ Para Iamarino $^{32}$ toda métrica tem seus pontos fortes e fracos. Quanto mais métricas são usadas em conjunto, mais difícil fica de trapacear. A "Tabela 6" apresenta o impacto das principais revistas publicadas pelo ResearchGate, baseado na contagem média de citações do trabalho, ainda que os dados utilizados no cálculo não sejam exaustivos. ${ }^{33}$

\footnotetext{
${ }^{30}$ GARFIELD, E., Journal impact factor, p. 979-980.

${ }^{31}$ KRAKER, P.; JORDAN, K.; LEX, E., The ResearchGate Score.

${ }^{32}$ IAMARINO, A., Métricas alternativas.

${ }^{33}$ JORDAN, K., Exploring the ResearchGate score as an academic metric.
} 
Tabela 6: Principais artigos segundo fator de impacto ResearchGate e Google Scholar

\begin{tabular}{l|l|l|c|c}
\hline $\begin{array}{l}\text { Ranking } \\
\text { RG }\end{array}$ & Título artigo & $\begin{array}{l}\text { Título } \\
\text { periódico }\end{array}$ & $\begin{array}{c}\text { Fator de } \\
\text { impacto }\end{array}$ & $\begin{array}{c}\text { Ranking } \\
\text { GS }\end{array}$ \\
\hline $1^{\text {o }}$ & $\begin{array}{l}\text { The effects of maternal parenting style } \\
\text { and religious commitment on self- } \\
\text { regulation, academic achievement, } \\
\text { and risk behavior among African- } \\
\text { American parochial college students }\end{array}$ & $\begin{array}{l}\text { Journal of } \\
\text { adolescence }\end{array}$ & 1.15 & $1^{\text {o }}$ \\
\hline $2^{\text {o }}$ & $\begin{array}{l}\text { Alienation from Religion in } \\
\text { Adolescents from Fundamentalist } \\
\text { Religious Homes }\end{array}$ & $\begin{array}{l}\text { Journal for the } \\
\text { Scientific Study } \\
\text { of Religion }\end{array}$ & 0.89 & $8^{\text {o }}$ \\
\hline $2^{\text {o }}$ & $\begin{array}{l}\text { Family Worship Patterns and Their } \\
\text { Correlation with Adolescent Behavior } \\
\text { and Beliefs }\end{array}$ & $\begin{array}{l}\text { Journal for the } \\
\text { Scientific Study } \\
\text { of Religion }\end{array}$ & 0.89 & $7^{\mathbf{0}}$ \\
\hline $2^{\text {o }}$ & $\begin{array}{l}\text { Religious Factors and Drug Usage } \\
\text { among Seventh-Day Adventist Youth } \\
\text { in North America }\end{array}$ & $\begin{array}{l}\text { Journal for the } \\
\text { Scientific Study } \\
\text { of Religion }\end{array}$ & 0.89 & $5^{\mathbf{o}}$ \\
\hline $5^{\text {o }}$ & $\begin{array}{l}\text { Alienation from Religion in Church- } \\
\text { Related Adolescents }\end{array}$ & $\begin{array}{l}\text { Sociology of } \\
\text { Religion }\end{array}$ & 0.45 & $11^{\mathbf{o}}$ \\
\hline
\end{tabular}

É possivel afirmar que o artigo The effects of maternal parenting style and religious commitment on self-regulation, academic achievement, and risk behavior among African-American parochial college students é o mais citado, em ambas as plataformas, sobre o tema. Entre os cinco artigos mais populares, religiosidade, comportamento e crenças dos adolescentes estão novamente presentes entre os temas mais abordados.

Figura 4: Nuvem de palavras nos títulos de periódicos

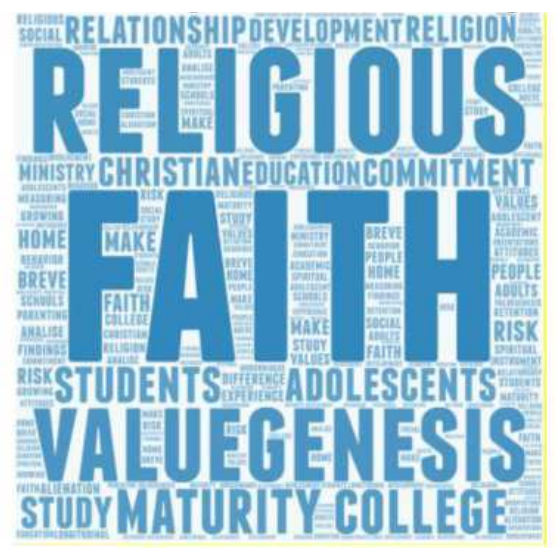


No que se refere aos títulos dos estudos publicados em periódicos, observa-se que a maior parte dos termos também se refere ao conceito de fé, tema que tem se mostrado o mais analisado nas pesquisas que tratam sobre a juventude adventista. O termo Valuegenesis é um dos que ganha destaque, diante da relevância desse estudo longitudinal, indicando que boa parte de artigos em periódicos o analisa ou o repercute.

\section{Conclusão}

O presente artigo procurou propor elementos para um estado da arte de pesquisas tendo a juventude adventista como foco e/ou objeto de pesquisa a partir de um inventário bibliográfico em língua inglesa e portuguesa de estudos em dissertações, teses, livros, artigos científicos e equivalentes de 1975 a 2018 sobre a temática. Com esse levantamento, espera-se contribuir com a sistematização, organização, análise e compreensão da produção de conhecimento relacionado à juventude adventista, cujo resultado seja um ponto-de-partida para a construção de um estado da arte sobre a intersecção juventude/adventismo no circuito acadêmico anglófono e brasileiro. Um inventário bibliográfico das pesquisas sobre juventude adventista necessita levar em consideração levantamentos prévios, dos quais se destacam os estudos de Brantley e Novaes e Follis. A partir deles, constata-se que a maior parte dos trabalhos é em língua inglesa, de forma que estudos sobre a juventude adventista no Brasil e em países de fala portuguesa são ainda incipientes e, por essa razão, campo de pesquisa promissor a ser desbravado.

No levantamento, foram procuradas dissertações ou teses, livros, capítulos de livros, artigos de periódicos, artigos de congresso (oral ou pôster) e relatórios institucionais com a presença, nos títulos dos estudos, dos termos "adventist", "SDA ", “youth", "young", “millenials", "valuegenesis" em inglês, e os termos "adventista", "adventismo", "IASD", "jovem", "jovens", "juventude", "juvenil" em português. O levantamento ocorreu de julho a agosto de 2018 e foram encontrados 121 trabalhos acadêmicos, a maior parte deles artigos de periódicos, dissertações ou teses. Dos 121 trabalhos encontrados, destaca-se a importância e a relevância da pesquisa Valugenesis, estudo longitudinal que representa uma boa parte dos estudos da amostra, que repercutem seus resultados. 
Após análise bibliométrica aplicada ao corpus, afirma-se que as sequências de anos 2002-2004 e 2014-2015 foram os períodos mais profícuos nas pesquisas sobre jovens adventistas, a maior parte deles em inglês. Conforme aplicação da técnica de nuvem de palavras para mensurar os temas mais recorrentes nos títulos dos estudos do corpus, percebe-se que pesquisas ligadas à educação, com foco na influência das relações parentais, da igreja e da escola sobre o desenvolvimento da fé são as mais recorrentes. Dessa forma, com o levantamento feito e com os elementos para um estado da arte reunidos neste artigo, tem-se um retrato razoavelmente preciso sobre as características, temas e tendências das pesquisas cujo objeto é a juventude adventista.

\section{Referências bibliográficas}

ABAR, B.; CARTER, K. L.; WINSLER, A. The effects of maternal parenting style and religious commitment on self-regulation, academic achievement, and risk behavior among African-American parochial college students. Journal of adolescence, v.32, n.2, p. 259-273, 2009.

BARNA GROUP. The Seventh day Adventist Millennial Study. Barna Group: Ventura / California, 2013.

BRANTLEY, P. A compilation of studies related to Seventh-day Adventist youth and young adults and their attitudes toward spirituality and the church. Berrien Springs: Andrews University, 2013. Disponível em: $<$ https:// gleanernow.com/feature/excerpts-barna-study-adventist-millennials $>$. Acesso em: 9 out. 2018.

CARDOSO, R.; SAMPAIO, H. (Orgs.). Bibliografia sobre a juventude. São Paulo: Editora da Universidade de São Paulo, 1995.

DIAS, M. A. et al. Intersetorialidade e Estratégia Saúde da Família: tudo ou quase nada a ver? Ciência \& Saúde Coletiva, v.19, n.11, p. 4371-4382, 2014.

DUDLEY, R. L. Valuegenesis: Faith in the Balance: a Project Affirmation Publication. La Sierra: La Sierra University Press, 1992.

DUDLEY, R. L. Understanding the spiritual development and the faith experience of college and university students on Christian campuses. Journal of Research on Christian Education, v.8, n.1, p. 5-28, 1999. 
DUDLEY, R. L.; DUDLEY, M. G. Transmission of religious values from parents to adolescents. Review of Religious Research, v.28, n.1, p. 3-15, set. 1986.

FERREIRA, B. et al. O crescimento do Reino: desafios demográficos para o adventismo brasileiro. In: FOLLIS, R.; NOVAES, A.; DIAS, M. (Orgs.). Sociologia e adventismo: desafios brasileiros para a missão. Engenheiro Coelho: Unaspress, 2017.

FERREIRA, N. A. As pesquisas denominadas "estado da arte". Revista Educação \& Sociedade, v.23, n.79, p. 257-272, ago. 2002.

FONSECA, A. B. Muito além do sábado: o pioneirismo adventista na mídia eletrônica religiosa. Revista de Estudos da Religião, v.8, n.3, p. 89-100, jul./ set. 2008. Disponível em: <http://www.pucsp.br/rever/rv3_2008/t_fonseca. pdf $>$. Acesso em: 9 out. 2018.

FUCKNER, I. A Igreja Adventista do Sétimo Dia entre a modernidade e a pósmodernidade. Mosaico, v.5, n.2, p. 159-169, jul./dez. 2012. Disponível em: $<$ http://seer.ucg.br/index.php/mosaico/article/viewFile/2501/1556>. Acesso em: 24 set. 2018.

FURTADO, K. Representações escatológico-sabático-dietéticas de jovens da Igreja Adventista do Sétimo Dia. Ponta Grossa, 2014. Dissertação. 367p. Mestrado em Sociedade, Direito e Cidadania, Universidade Federal de Ponta Grossa.

GARFIELD, E. Journal impact factor: a brief review. Canadian Medical Association Journal, v.161, n.8, p. 979-980, out. 1999.

IAMARINO, A. Métricas alternativas: Introdução para autores e avaliadores. Com ciência: revista eletrônica de divulgação científica, n. 197, s/p, abr. 2018. Disponível em: <http://www.comciencia.br/metricas-alternativas-umaintroducao-para-autores-e-avaliadores/>. Acesso em: 9 out. 2018.

JORDAN, G. Perception of values relating to character development: a study of college students' views on a Seventh-day Adventist campus. Berrien Springs, 1975. Tese. School of Graduate Studies, Andrews University.

JORDAN, K. Exploring the ResearchGate score as an academic metric: reflections and implications for practice. In: Quantifying and Analysing Scholarly Communication on the Web (ASCW15), 2015, Oxford. Anais 
do ACSW'15. Oxford, 2015. Disponível em: <http://ascw.know-center. tugraz.at/2015/06/22/jordan-k-exploring-the-researchgate-score-as-anacademic-metric-reflections-and-implications-for-practice $>$. Acesso em: 9 out. 2018.

KRAKER, P.; JORDAN, K.; LEX, E. The ResearchGate Score: a good example of a bad metric. In: Quantifying and Analysing Scholarly Communication on the Web (ASCW15), 2015, Oxford. Anais do ACSW'15. Oxford, 2015. Disponível em: <http://ascw.know-center. tugraz.at/2015/05/26/kraker-lex-a-critical-look-at-the-researchgatescore >. Acesso em: 9 out. 2018.

LEMOS, F. Comunicação é ênfase estratégica de adventistas para os próximos cinco anos. Notícias adventistas, Brasília, 3 nov. 2015. Disponível em: <https://noticias.adventistas.org/pt/noticia/comunicacao/ comunicacao-e-enfase-estrategica-de-adventistas-para-proximos-cincoanos>. Acesso em: 13 mar. 2019.

NOVAES, A.; FOLLIS, R. (Orgs.). O adventismo na academia brasileira: um panorama do estado da arte. Engenheiro Coelho: Unaspress, 2016.

RIBEIRO, L. M. P. O protestantismo brasileiro: objeto em estudo. Revista USP, n.73, p. 117-129, mar./mai. 2007. Disponível em: <http://www. revistas.usp.br/revusp/article/view/13593>. Acesso em: 9 out. 2018.

ROMANOWSKI, J. P.; ENS, R. T. As pesquisas denominadas do tipo "estado da arte" em educação. Diálogo Educ., v.6, n.19, p. 37-50, set./ dez. 2006.

SPOSITO, M. (Org.). O Estado da arte sobre a juventude na pós-graduação brasileira: Educação, Ciências Sociais e Serviço Social (1999-2006). Belo Horizonte: Argumentum, 2009. v.1 e v.2.

TAGUE-SUTCLIFFE, J. An introduction to informetrics. Information processing \& management, v.28, n.1, p. 1-3, 1992.

TAVARES, F. R.; CAMURÇA, M. "Juventudes" e religião no Brasil: uma revisão bibliográfica. Numen: revista de estudos e pesquisa de religião, v.7, n.1, p. 11-46, jan./jun. 2004.

TETZ, M.; HOPKINS, G. L. We can keep them in the church. Nampa: Pacific Press, 2004. 
THAYER, J. D. Measuring faith maturity: Reassessing Valuegenesis and development of a denomination-specific scale. Journal of Research on Christian Education, v.2, n.1, p. 93-113, 1993.

\author{
Allan Novaes \\ Doutor em Ciência da Religião pela Pontifícia Universidade Católica \\ de São Paulo \\ Docente da Faculdade de Teologia do Centro Universitário Adventista de \\ São Paulo \\ Engenheiro Coelho / SP - Brasil \\ E-mail: allan.novaes@unasp.edu.br
}

Recebido em: 30/09/18

Aprovado em: 05/12/18 